\title{
Observational study to characterise 24-hour COPD symptoms and their relationship with patient-reported outcomes: results from the ASSESS study
}

Marc Miravitlles ${ }^{1 *}$, Heinrich Worth², Juan José Soler Cataluña ${ }^{3}$, David Price ${ }^{4}$, Fernando De Benedetto $^{5}$, Nicolas Roche ${ }^{6}$, Nina Skavlan Godtfredsen ${ }^{7}$, Thys van der Molen ${ }^{8}$, Claes-Göran Löfdahl ${ }^{9}$, Laura Padullés ${ }^{10}$ and Anna Ribera ${ }^{10}$

\begin{abstract}
Background: Few studies have investigated the 24-hour symptom profile in patients with COPD or how symptoms during the 24-hour day are inter-related. This observational study assessed the prevalence, severity and relationship between night-time, early morning and daytime COPD symptoms and explored the relationship between 24-hour symptoms and other patient-reported outcomes.

Methods: The study enrolled patients with stable COPD in clinical practice. Baseline night-time, early morning and daytime symptoms (symptom questionnaire), severity of airflow obstruction $\left(F E V_{1}\right)$, dyspnoea (modified Medical Research Council Dyspnoea Scale), health status (COPD Assessment Test), anxiety and depression levels (Hospital Anxiety and Depression Scale), sleep quality (COPD and Asthma Sleep Impact Scale) and physical activity level (sedentary, moderately active or active) were recorded.

Results: The full analysis set included 727 patients: $65.8 \%$ male, mean \pm standard deviation age $67.2 \pm 8.8$ years, $\%$ predicted FEV $152.8 \pm 20.5 \%$.

In each part of the 24 -hour day, $>60 \%$ of patients reported experiencing $\geq 1$ symptom in the week before baseline. Symptoms were more common in the early morning and daytime versus night-time $(81.4 \%, 82.7 \%$ and $63.0 \%$, respectively). Symptom severity was comparable for each period assessed. Overall, in the week before baseline, 56.7\% of patients had symptoms throughout the whole 24 -hour day ( 3 parts of the day); $79.9 \%$ had symptoms in $\geq 2$ parts of the 24-hour day. Symptoms during each part of the day were inter-related, irrespective of disease severity (all $p<0.001$ ). Early morning and daytime symptoms were associated with the severity of aiffow obstruction ( $p<0.05$ for both). Nighttime, early morning and daytime symptoms were all associated with worse dyspnoea, health status and sleep quality, and higher anxiety and depression levels (all $p<0.001$ versus patients without symptoms in each corresponding period). In each part of the 24-hour day, there was also an association between symptoms and a patient's physical activity level ( $p<0.05$ for each period).

(Continued on next page)
\end{abstract}

\footnotetext{
*Correspondence: mmiravitlles@vhebron.net

${ }^{1}$ Pneumology Department, Hospital Universitari Vall d'Hebron, Ciber de Enfermedades Respiratorias (CIBERES), P. de la Vall d'Hebron, 119-129, Barcelona, Spain

Full list of author information is available at the end of the article
}

\section{Biomed Central}

(c) 2014 Miravitlles et al.; licensee BioMed Central Ltd. This is an Open Access article distributed under the terms of the Creative Commons Attribution License (http://creativecommons.org/licenses/by/4.0), which permits unrestricted use, distribution, and reproduction in any medium, provided the original work is properly credited. The Creative Commons Public Domain Dedication waiver (http://creativecommons.org/publicdomain/zero/1.0/) applies to the data made available in this article, unless otherwise stated. 
(Continued from previous page)

Conclusions: More than half of patients experienced COPD symptoms throughout the whole 24-hour day. There was a significant relationship between night-time, early morning and daytime symptoms. In each period, symptoms were associated with worse patient-reported outcomes, suggesting that improving 24-hour symptoms should be an important consideration in the management of COPD.

Keywords: Anxiety, ASSESS, COPD, Depression, Dyspnoea, Health status, Observational, Relationship, Sleep quality, Symptoms

\section{Background}

Despite being preventable and treatable, chronic obstructive pulmonary disease (COPD) is associated with considerable morbidity and mortality $[1,2]$ and its prevalence is expected to increase in the coming decades [3]. The characteristic symptoms of COPD include breathlessness, cough and increased sputum production and, based on cohort studies, there is now extensive evidence that COPD symptoms have a considerable impact on patients' daily activities, health status and quality of life [4-8]. Furthermore, while COPD is diagnosed clinically based on persistent airflow limitation, it is the impact of symptoms on patients' daily lives that generally drives them to seek a diagnosis. The importance of considering COPD symptoms in the overall assessment of COPD, and in determining appropriate treatment approaches, is now recognised [9]. Reducing symptoms, improving health status and increasing physical activity are major goals in the management of stable COPD [9].

COPD symptoms have been reported to vary throughout the day [10-12]. In cohort studies, patients with COPD who were receiving ongoing treatment with their normal COPD medication reported that their symptoms were worst in the morning $[10,12]$. Morning symptoms impact on patients' normal activities $[8,10,12,13]$ and have been demonstrated to be associated with worse health status and a higher risk of COPD exacerbations $[8,13]$. In the working population, morning symptoms were also significantly associated with increased annual absenteeism [13]. With regard to night-time symptoms, a recent real-world study also demonstrated that patients with night-time symptoms had significantly worse health status, more sleep disturbances and higher healthcare resource utilisation than patients without nighttime symptoms [7].

In a pan-European, observational study, patients' perception of the variability of their breathlessness was associated with both the severity of breathlessness and frequent exacerbations [10], while the pattern of COPD symptom variability has been shown to be influenced by disease severity [12]. Previous studies have also shown an association between morning or night-time symptoms and reduced lung function $[7,13,14]$. However, the association between symptoms in each part of the 24-hour day and the severity of airflow obstruction and the inter-relationship between 24-hour COPD symptoms has not previously been investigated in a single patient cohort.

In this observational study, we investigated the prevalence and severity of night-time, early morning and daytime symptoms in patients with stable COPD being treated in clinical practice and explored the relationship between symptoms in each part of the 24-hour day. Additionally, to better understand the relationship between 24-hour symptoms and other aspects of a patient's overall well-being, we assessed their association with the severity of airflow obstruction and other patientreported outcomes, including self-perceived dyspnoea, health status, anxiety and depression levels, sleep quality and physical activity level.

\section{Methods}

\section{Study design}

This was a multinational, non-interventional, observational study conducted in 85 clinical practice centres (pulmonologists outpatients and primary care) across Denmark, France, Germany, Italy, The Netherlands, Spain, Sweden and UK (see Additional file 1 for a list of investigators). Patients who met the eligibility criteria were identified consecutively at each site, with each site having a maximum quota to minimise selection bias. The study consisted of a baseline visit (Day 1) and a follow-up telephone interview after 6 months. There were no interventions beyond routine clinical care delivered at the discretion of the physician.

A steering committee, comprising the study country co-ordinators, was involved in the design of the study. The protocol was approved by all necessary ethics committees, as required by law for each country, before study initiation (see Additional file 2 for a list of approval authorities for each country). All patients provided written informed consent.

\section{Study population}

Patients were aged $\geq 40$ years with mild to very severe COPD according to the Global Initiative for Chronic 
Obstructive Lung Disease (GOLD) spirometric classification [15], (spirometry data from the year before baseline were considered valid). Patients were current or former smokers with a smoking history of $\geq 10$ pack-years and had no history of COPD exacerbation in the previous month.

Exclusion criteria were: any change in maintenance COPD treatment in the previous 3 months; a previous diagnosis of asthma, sleep apnoea syndrome or chronic respiratory disease other than COPD; and any acute or chronic condition that would limit the patient's ability to complete the questionnaires.

\section{Assessments}

Night-time, early morning and daytime symptoms, severity of airflow obstruction, dyspnoea severity, health status, anxiety and depression levels, sleep quality and physical activity levels were assessed at baseline. COPD symptoms were assessed using a Night-time, Morning and Daytime Symptoms of COPD questionnaire developed by the study sponsor. To ensure accurate translation and a clear understanding of the questionnaire in each participating country, linguistic validation based on five patients per country was performed before use of the questionnaire in the study. The Night-time, Morning and Daytime Symptoms of COPD questionnaire is a 33-item questionnaire that asks the patient about the prevalence, frequency and severity of COPD symptoms during each part of the day during (i) the week before baseline and (ii) a typical week in the month before baseline (defined as a week the patient considers most usual for them in the previous month). In addition, the questionnaire also contained questions related to sleep disturbances, rescue medication, anxiety due to symptoms, limitation of activities due to symptoms and concentration levels. The questionnaire consists of three parts (one part for each period during the 24-hours) and includes 13 items for night-time symptoms, ten items for morning symptoms and ten items for daytime symptoms. Night-time corresponds to the time from when the patient goes to bed until they get out of bed to start the day; morning is the time from getting out of bed until approximately $11 \mathrm{am}$; and daytime is from approximately 11 am until the patient goes to bed. Patients were asked about the frequency of symptoms related to breathlessness, coughing, bringing up phlegm or mucus, chest tightness, chest congestion and wheezing during each period. Patients were also asked about the overall severity of their night-time, early morning and daytime symptoms during the last week; symptom severity was scored as 1 (no symptoms); 2 (mild); 3 (moderate); 4 (severe) or 5 (very severe).

Dyspnoea was assessed using the modified Medical Research Council (mMRC) scale [16] with patients assessing their perceived breathlessness on a scale of 0 (breathlessness with strenuous exercise) to 4 (too breathless to leave the house or breathless when dressing or undressing). Health status was assessed using the COPD Assessment Test (CAT; total score range $0-40,<10$ indicates low impact, 10-20 medium impact, 21-30 high impact, $>30$ very high impact on health status) [17]. Selfperceived anxiety and depression levels were assessed using the Hospital Anxiety and Depression Scale [18-21] (HADS; total score range $0-21$ where $\geq 8$ indicates a probable diagnosis $[22,23])$. Sleep quality was assessed using the COPD and Asthma Sleep Impact Scale (CASIS) $[24,25]$. Patients assessed the frequency of a range of sleep problems on a scale of 1 (never) to 5 (very often; several items are reverse-scored); individual item scores were summed to give a total raw score, which was linearly transformed to total scale score (range 1-100); higher scores indicate greater sleep impairment. At baseline, patients were also assessed as being sedentary (does not perform any type of physical activity), moderately active (patient performs some type of exercise two or three times a week) and active (patient plays sports or exercises more than three times a week).

\section{Study outcomes}

Primary endpoints in the study were the prevalence, severity, and inter-relationships for night-time, early morning and daytime symptoms at baseline (assessed based on the Night-time, Morning and Daytime Symptoms of COPD questionnaire). To further explore the relationship between 24-hour symptoms and other aspects of COPD that affect patients' well-being, secondary endpoints included the relationship between night-time, early morning and daytime symptoms and severity of COPD, dyspnoea severity, health status, levels of anxiety and depression, sleep quality and physical activity levels.

\section{Statistical analyses}

All analyses were performed using the full analysis set, which comprised all patients who fulfilled the eligibility criteria and who completed the Night-time, Morning and Daytime Symptoms of COPD questionnaire. The data were analysed using only the available data for each outcome. Descriptive data are reported as mean \pm standard deviation (SD) or percentages, as appropriate. The relationship between symptoms in each part of the day and baseline characteristics or patient-reported outcomes was assessed using univariate analysis. The relationship between symptoms in each part of the day, symptoms and airflow limitation, symptoms and comorbidities and symptoms and physical activity level was assessed using a chi-squared test. The relationship between night-time, early morning or daytime symptoms and dyspnoea, health status, anxiety and depression levels, and sleep quality was assessed using a Wilcoxon 
rank sum test. All statistical tests were two-sided and used a 5\% significance level; there was no adjustment for multiplicity. All statistical analyses were performed using SAS (version 9.1.3 or later; SAS Institute Inc., Cary, NC, USA).

A sample size of 680 patients offered a maximum margin of error (minimum precision) of $4 \%$ for estimating the percentage of patients with night-time, early morning and daytime symptoms, considering maximum indetermination $(\mathrm{p}=50 \%)$ and a confidence level of $95 \%$. Anticipating that approximately $5 \%$ of patients would have missing data or a major protocol violation, the final sample size was set at 720 patients.

\section{Results}

\section{Patients}

Of 743 patients who enrolled in the study and had a baseline visit, 727 were eligible for inclusion in the full analysis set. Demographics and baseline characteristics are shown in Table $1 ; 72.4 \%$ of patients had a diagnosis of moderate or severe COPD (based on severity of airflow limitation) and 58.9\% had dyspnoea assessed on the mMRC scale as grade $\geq 2$. Overall, $50.9 \%$ of patients were receiving treatment with triple therapy (long-acting $\beta_{2}$-agonists [LABA], long-acting muscarinic antagonists [LAMA] plus inhaled corticosteroids), with or without a phosphodiesterase 4 (PDE4) inhibitor $(2.1 \%$ and $48.8 \%$, respectively). In addition to COPD, $79.4 \%$ of patients had a comorbid medical condition; $45.1 \%$ of patients had a diagnosis of hypertension and $33.7 \%$ had cardiovascular disease. Based on physical activity level, 30.0\% of patients were assessed as being sedentary, 38.1\% as moderately active and $31.4 \%$ as active at baseline.

\section{Prevalence and severity of COPD symptoms in each part of the 24-hour day}

The prevalence of COPD symptoms in each part of the 24-hour day is shown in Figure 1. In each part of the 24-hour day, $>60 \%$ of patients experienced at least one COPD symptom in the week before baseline (Figure 1). Early morning and daytime symptoms were most common, however $63.0 \%$ of patients experienced at least one night-time symptom in the week before baseline and more than half of the patients $(52.0 \%)$ reported having night-time symptoms at least three times during a typical week.

Patients' assessment of the severity of their night-time, early morning and daytime symptoms is shown in Table 2. In symptomatic patients the overall severity of symptoms was comparable for the night-time, early morning and daytime periods (Table 2). In each part of the 24-hour day, most people assessed their symptoms during the previous week as mild or moderate (nighttime $89.5 \%$, early morning $87.9 \%$ and daytime $89.3 \%$ ).

\section{Individual COPD symptoms}

When individual symptoms were assessed, symptoms related to breathlessness were most common (71.4\% of patients) followed by coughing (65.9\%), bringing up phlegm or mucus (59.6\%), wheezing (41.4\%), chest tightness (32.9\%) and chest congestion (23.4\%). The frequency and pattern of each individual symptom varied throughout the 24-hour day (Figure 2). The proportion of patients reporting breathlessness increased from night-time through the morning and into the daytime, whereas coughing and bringing up phlegm or mucus were most common early in the morning. Coughing and bringing up phlegm or mucus were the most common symptoms reported during the night-time.

\section{Relationship between COPD symptoms in each part of the 24-hour day}

In the week before baseline, $90.5 \%$ of patients experienced COPD symptoms during at least one part of the 24-hour day (Figure 3). More than half of patients (56.7\%) experienced symptoms throughout the whole 24-hour day; $10.6 \%$ of patients had symptoms in only one part (Figure 3). Almost $60 \%$ of patients had both night-time and early morning symptoms (Table 3). Among patients with night-time symptoms, 94.3\% also had early morning symptoms while $73.3 \%$ of those with early morning symptoms also had night-time symptoms. A similar pattern was observed for the combinations of night-time and daytime symptoms (Table 3 ).

When the relationships between symptoms during each part of the 24-hour day were assessed, there was a significant association for each potential symptom combination (night-time and early morning symptoms; night-time and daytime symptoms; and early morning and daytime symptoms; all $\mathrm{p}<0.001$ ). The relationships between night-time, early morning and daytime symptoms were maintained for all symptom combinations, irrespective of the severity of airflow limitation (mild to very severe all $\mathrm{p}<0.05$ ).

\section{Relationship between COPD symptoms in each part of the 24-hour day and other aspects of COPD}

The overall proportion of patients with any COPD symptom and the prevalence of night-time, early morning and daytime symptoms, according to COPD severity (based on airflow limitation) are shown in Figure 4A and B. Irrespective of the severity of airflow obstruction, $>80 \%$ of patients in each severity category experienced COPD symptoms (Figure 4A). Overall, there was a significant relationship between COPD severity and symptoms during the early morning and the daytime (both $\mathrm{p}<0.05$ ). However, the relationship between night-time symptoms and COPD severity did not reach statistical significance and the proportion of patients with night-time symptoms was 
Table 1 Demographics and baseline characteristics

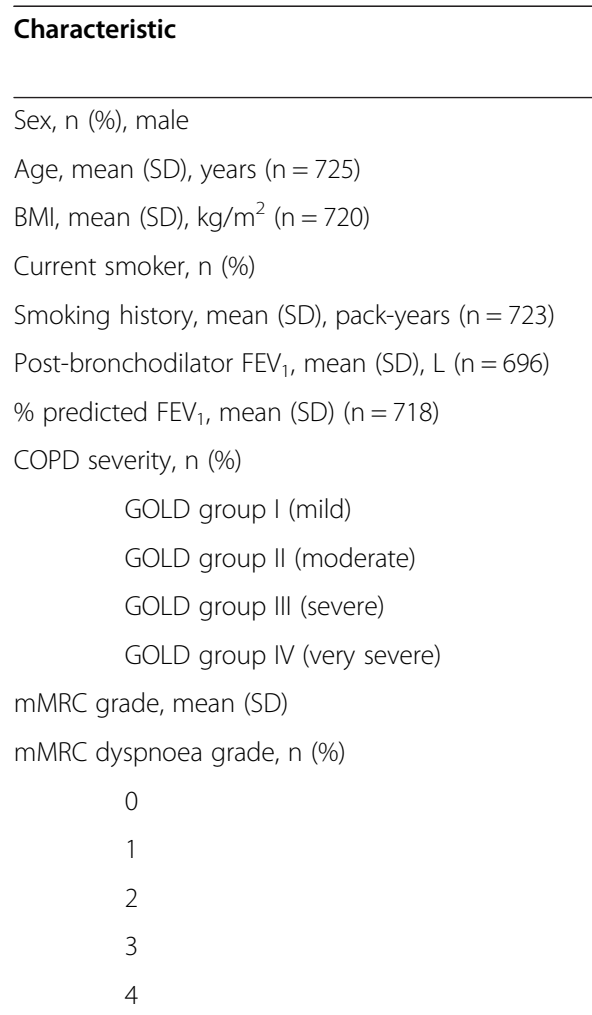

Patients with an exacerbation in previous year, $\mathrm{n}(\%)$

Number of COPD exacerbations in previous year, mean (SD) $(n=724)$

Current COPD medication, $\mathrm{n}(\%)^{\mathrm{a}}$

LABAs + LAMAs + ICS
LABAs + ICS
LABAs + LAMAs
LABAs alone
LAMAs alone
Short-acting bronchodilators ${ }^{\text {b }}$
LABAs + LAMAs + ICS + PDE4 inhibitor $^{\text {LAMAs + ICS }}$
Other $^{C}$

No treatment

Total CAT score, mean (SD) $(n=721)$

$16.5(8.1)$

CAT score category, $\mathrm{n}(\%)$

$$
\begin{aligned}
& \text { CAT score } \leq 10, \mathrm{n}(\%) \\
& \text { CAT score 11-20, n (\%) } \\
& \text { CAT score 21-30, n (\%) } \\
& \text { CAT score }>30, \mathrm{n}(\%)
\end{aligned}
$$

Table 1 Demographics and baseline characteristics (Continued)

\begin{tabular}{lc}
\hline HADS anxiety score, mean (SD) $(n=710)$ & $6.1(4.2)$ \\
HADS depression score, mean (SD) $(n=714)$ & $5.5(4.1)$ \\
CASIS score, mean (SD) $(n=712)$ & $44.1(19.1)$ \\
\hline $\mathrm{n}=$ patients with available data for each outcome; percentages are based on \\
$\mathrm{N}=727$ patients. \\
a Used by >1\% of patients. \\
bIncludes: SABA alone; SABA + SAMA; SAMA alone. \\
Includes: ICS alone; ICS + PDE4 inhibitor; LABA + ICS + PDE4 inhibitor; \\
LAMA + LABA + PDE4 inhibitor. \\
BMI, body mass index; CASIS, COPD and Asthma Sleep Impact Scale; CAT, COPD \\
Assessment Test; COPD, chronic obstructive pulmonary disease; FEV 1 , forced \\
expiratory volume in 1 second; GOLD, Global Initiative for Chronic Obstructive Lung \\
Disease; HADS, Hospital Anxiety and Depression Scale; ICS, inhaled corticosteroid; \\
LABA, long-acting $\beta_{2}$-agonist; LAMA, long-acting muscarinic antagonist; mMRC, \\
modified Medical Research Council; PDE4, phosphodiesterase 4; SABA, short-acting \\
$\beta_{2}$ agonist; SAMA, short-acting muscarinic antagonist; SD, standard deviation.
\end{tabular}

similar across all severities (58.9-65.9\%; Figure 4B). Interestingly, there was also no significant relationship between COPD severity and the number of parts of the 24-hour day when patients experienced symptoms $(\mathrm{p}=0.125)$; $47.6 \%$ of patients with mild COPD reported symptoms during the whole 24-hour day during the week before baseline compared with $63.0 \%$ of patients with very severe COPD.

There was a significant relationship between nighttime, early morning and daytime symptoms and the severity of self-perceived dyspnoea (all p $<0.001$; Table 4). Mean mMRC grades were significantly higher in patients with symptoms compared with patients without symptoms in each corresponding part of the 24-hour day (Table 4). There was also an association between the number of parts of the 24-hour day when patients experienced symptoms and dyspnoea severity $(\mathrm{p}<0.001)$. Most patients who had grade $\geq 2$ dyspnoea assessed on the mMRC dyspnoea scale had symptoms throughout the whole 24-hour day (63.8\%); this compares with $46.5 \%$ of patients assessed as mMRC grade $<2$. There was no significant relationship between night-time, early morning or daytime symptoms and the presence of comorbidities in these patients.

In each part of the 24-hour day, including night-time, there was a significant relationship between symptoms and health status, anxiety and depression levels, and sleep quality (all $\mathrm{p}<0.001$ versus no symptoms; Table 4 ). In each period, mean CAT scores were $>7.5$ points higher in patients with symptoms versus patients without symptoms (Table 4). Based on HADS score at baseline, $34.5 \%$ of patients had anxiety and $27.6 \%$ had depression. When assessed according to patients with and without symptoms in each part of the 24-hour day, mean HADS anxiety and depression scores were significantly higher in patients with symptoms versus those without symptoms ( $<0.001$ for all; Table 4$)$. Sensitivity analyses performed in patients with no medical history 


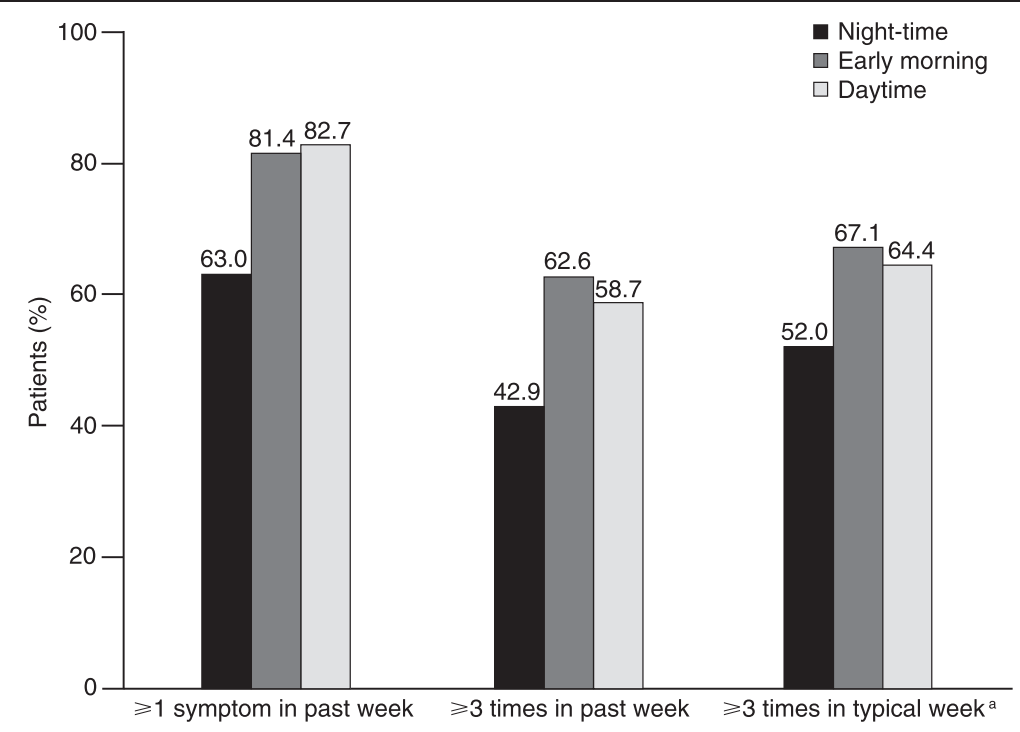

Figure 1 Prevalence and frequency of night-time, early morning and daytime COPD symptoms $(\mathbf{N}=\mathbf{7 2 7})$. ${ }^{\mathrm{a}} \mathrm{A}$ typical week refers to a week that the patient considered most usual for them during the previous month. COPD, chronic obstructive pulmonary disease.

of anxiety $(\mathrm{n}=534)$ or depression $(\mathrm{n}=538)$ also showed a significant association between symptoms and HADS anxiety and depression scores in each part of the 24-hour day (all $\mathrm{p}<0.001$ ). Patients with symptoms also had significantly higher CASIS scores compared with those without symptoms ( $\mathrm{p}<0.001$ for all; Table 4$)$, indicating greater sleep impairment. When patients who were receiving sleep medications or treatment for benign prostatic hyperplasia $(n=109)$ were excluded from the analyses of CASIS scores, the relationship between night-time, early morning and daytime symptoms and sleep quality remained significant in each period (data not shown).

In each part of the 24-hour day, there was a significant relationship between symptoms and patients' physical activity level at baseline (assessed as sedentary, moderately active or active; $\mathrm{p}<0.05$ for each part of the 24-hour day). There was also a significant relationship for the number of parts of the 24-hour day when patients

Table 2 Patients' assessment of night-time, early morning and daytime symptom severity in the week before baseline

\begin{tabular}{llll}
\hline $\begin{array}{l}\text { Symptom } \\
\text { severity }\end{array}$ & \multicolumn{3}{l}{ No. of patients $\mathbf{( \% )}$} \\
\cline { 2 - 4 } & $\begin{array}{l}\text { Night-time } \\
\left(\mathbf{n}=\mathbf{4 0 9}^{\mathbf{a}}\right)\end{array}$ & $\begin{array}{l}\text { Early morning } \\
\left(\mathbf{n}=\mathbf{5 7 1}^{\mathbf{a}}\right)\end{array}$ & $\begin{array}{l}\text { Daytime } \\
\left(\mathbf{n}=\mathbf{5 8 9}^{\mathbf{a}} \mathbf{)}\right.\end{array}$ \\
\hline Mild & $191(46.7)$ & $252(44.1)$ & $254(43.1)$ \\
Moderate & $175(42.8)$ & $250(43.8)$ & $272(46.2)$ \\
Severe & $39(9.5)$ & $61(10.7)$ & $59(10.0)$ \\
Very severe & $4(1.0)$ & $8(1.4)$ & $4(0.7)$ \\
\hline
\end{tabular}

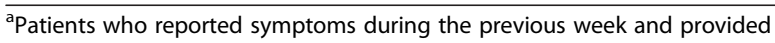
data for symptom severity.

COPD, chronic obstructive pulmonary disease. experienced symptoms and physical activity levels $(\mathrm{p}=0.006)$. A higher proportion of patients who were sedentary had symptoms throughout the whole 24-hour day compared with patients who were active (64.2\% versus $50.4 \%$, respectively).

Mean CAT, HADS anxiety and depression, and CASIS scores according to each 24-hour symptom combination are shown in Figure 5. Patients with symptoms throughout the whole 24-hour day had the worst health status and sleep quality and the highest levels of anxiety and depression. CAT scores were higher in patients with symptoms during two or more parts of the 24-hour day than in patients with only night-time, early morning or daytime symptoms (Figure 5A). With the exception of patients with early morning and daytime symptoms, patients who reported night-time symptoms, either alone or in combination, had the highest anxiety levels (Figure 5B) and patients with any combination of early morning and night-time symptoms had the highest depression levels (Figure 5C). A similar pattern was generally observed when HADS scores were analysed in patients with no medical history of anxiety or depression (Additional file 3). Patients with any night-time symptoms had worse sleep quality than patients without night-time symptoms (Figure 5D).

\section{Discussion}

In this observational study, more than half of patients reported experiencing COPD symptoms throughout the whole 24-hour day, despite receiving ongoing treatment for their COPD and almost $80 \%$ of patients had symptoms during at least two parts of the 24-hour day. While early morning and daytime symptoms were most frequent, 


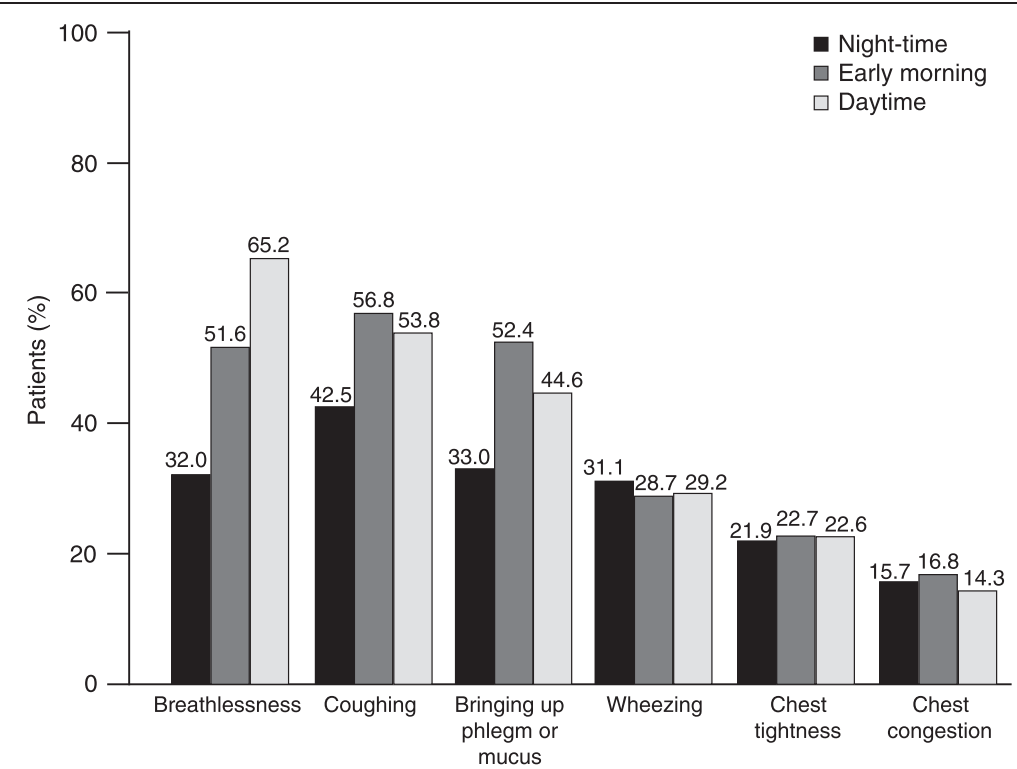

Figure 2 Prevalence of individual COPD symptoms throughout the 24 -hour day in the week before baseline $(\mathrm{N}=727)$. COPD, chronic obstructive pulmonary disease.

night-time symptoms were also very common and almost two-thirds of patients experienced at least one night-time symptom during the week before baseline. Importantly, any symptoms in the early morning, daytime or nighttime were associated with worse outcomes across a range of patient-reported measures including more severe dyspnoea, higher anxiety and depression levels and worse health status and sleep quality.
The observation that a large majority of patients experienced symptoms during at least two parts of the 24-hour day is consistent with results from a recent real-world study in almost 1500 patients. The study by Roche et al. showed that most patients had symptoms during the daytime and night-time and only $34 \%$ of patients experienced COPD symptoms in isolation during one part of the 24-hour day [13]. However, in contrast

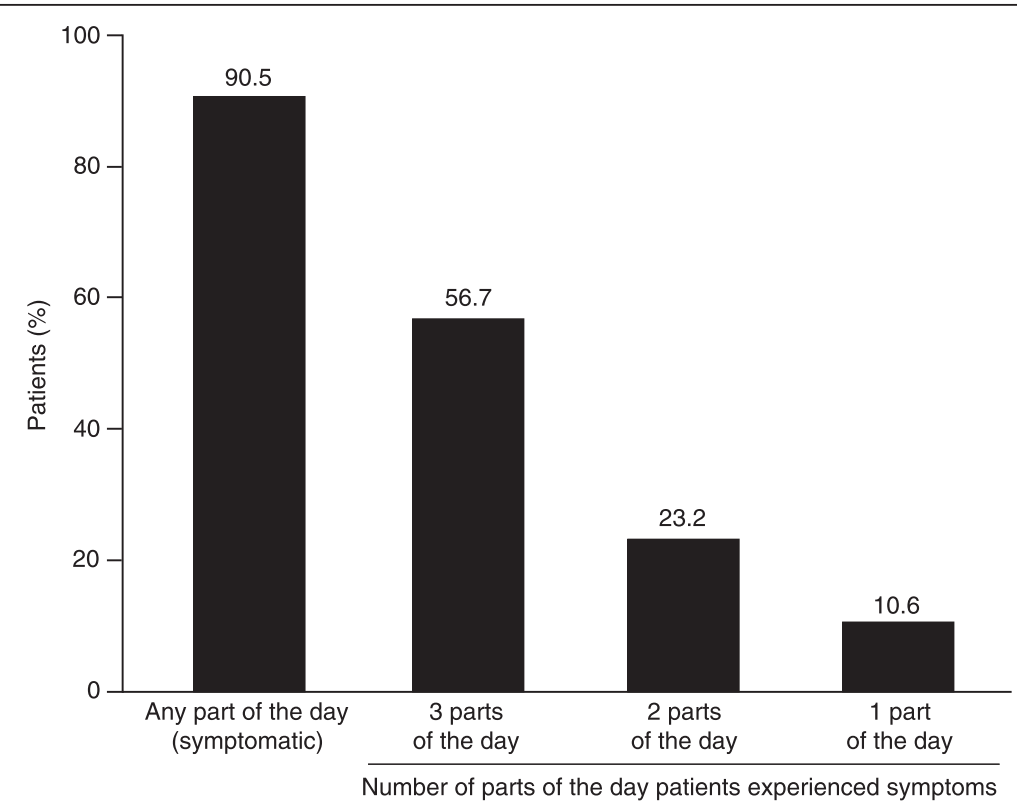

Figure 3 Prevalence of COPD symptoms during one, two or three parts of the 24-hour day in the week before baseline $(\mathrm{N}=727)$. COPD, chronic obstructive pulmonary disease. 
Table 3 Proportion estimates of night-time, early morning and daytime COPD symptom combinations

\begin{tabular}{|c|c|c|}
\hline Symptom combinations & $\%(n / N)$ & {$[95 \% \mathrm{Cl}]$} \\
\hline \multicolumn{3}{|l|}{ Night-time (NT) and early morning (EM) symptoms } \\
\hline Overall patients with both NT and EM symptoms & $59.8(432 / 723)$ & $56.1,63.3$ \\
\hline Patients with $\geq 1$ NT symptom $(n=458)$ who also had $\geq 1$ EM symptom & $94.3(432 / 458)$ & $91.8,96.1$ \\
\hline Patients with $\geq 1$ EM symptom $(n=589)$ who also had $\geq 1$ NT symptom & $73.3(432 / 589)$ & $69.6,76.8$ \\
\hline \multicolumn{3}{|l|}{ Night-time (NT) and daytime (DT) symptoms } \\
\hline Overall patients with both DT and NT symptoms & $59.4(429 / 722)$ & $55.8,62.9$ \\
\hline Patients with $\geq 1$ NT symptom $(n=458)$ who also had $\geq 1$ DT symptom & $93.7(429 / 458)$ & $91.1,95.6$ \\
\hline Patients with $\geq 1$ DT symptom $(n=598)$ who also had $\geq 1$ NT symptom & $71.7(429 / 598)$ & $68.0,75.2$ \\
\hline \multicolumn{3}{|l|}{ Early morning (EM) and daytime (DT) symptoms } \\
\hline Overall patients with both EM and DT symptoms & $75.0(544 / 725)$ & $71.7,78.1$ \\
\hline Patients with $\geq 1$ EM symptom $(n=591)$ who also had $\geq 1$ DT symptom & $92.1(544 / 591)$ & $89.6,94.0$ \\
\hline Patients with $\geq 1$ DT symptom $(n=601)$ who also had $\geq 1$ EM symptom & $90.5(544 / 601)$ & $87.9,92.6$ \\
\hline
\end{tabular}

to the results reported here, in the previous study daytime symptoms were by far the most prevalent (97\% of patients) with just over one-third of patients reporting symptoms when getting up in the morning. This discrepancy may relate to the different definitions of morning symptoms used; the Roche et al. study defined morning symptoms as those present on waking and did not include those symptoms that persisted later in the morning [13].

There is no objective definition of 'night-time symptoms' in patients with COPD, and it has been suggested that night-time symptoms may be under-reported by physicians or may not be reported by patients [26]. The results of our study are consistent with a previous study in 2807 patients, which demonstrated that approximately $70 \%$ of patients reported experiencing night-time symptoms [7]. Together these data suggest a high prevalence of night-time symptoms in patients with COPD. Lung function exhibits circadian variation with reduced airflow during the night-time period [27]. The amplitude of this circadian variation has been shown to be increased in patients with COPD [28,29] and it may contribute to night-time symptoms [26,28]. In a previous study, wheezing was the most troublesome symptom at night, followed by cough [10]. In the present study cough and bringing up phlegm were the most prevalent night-time symptoms suggesting that, in addition to reduced airflow, other mechanisms may be involved in mediating night-time symptoms including mucus hypersecretion, reduced ciliary activity or increased cough sensitivity. Further investigation of these processes is required to better understand the pathophysiology underlying night-time COPD symptoms.

Early morning symptoms have been reported to be most problematic for patients with COPD and can significantly impact on daily activities [10-12] and working life [13]. Furthermore, in a previous study, a quarter of patients with COPD reported that night-time symptoms were most troublesome and night-time was the second most problematic time for patients with severe COPD [12]. However, despite patients frequently reporting night-time symptoms, the impact that symptoms at night has on daily activities, such as getting up for work, is often under-estimated by physicians [7]. Previous studies have shown a significant association between night-time symptoms and the severity of airflow obstruction in patients with COPD $[7,14]$. Interestingly, our results show that whilst there was a significant relationship between early morning and daytime symptoms and the severity of airflow limitation, this association was not significant for night-time symptoms and the prevalence of night-time symptoms was comparable across all severities of airflow limitation. Furthermore, symptoms in each part of the 24-hour day were inter-related, an observation that was consistent irrespective of COPD severity. These data suggest that the presence of night-time symptoms is not merely a consequence of more severe airflow limitation. Other mechanisms, such as decreased mucociliary clearance, could be involved. However, this study did not differentiate between different phenotypes of patients with COPD and further studies are required to determine if night-time symptoms are associated with a specific phenotype.

In each part of the 24-hour day, symptoms were associated with worse dyspnoea, health status, higher anxiety and depression levels, and greater sleep impairment. These are all outcomes that can impact on patients' daily living and overall well-being. The difference in CAT scores between patients with and without symptoms in each period exceeded the estimated minimal clinically important difference (2 points) recently proposed [30], suggesting that symptoms in any part of the 24-hour day may be associated with a clinically meaningful worsening 


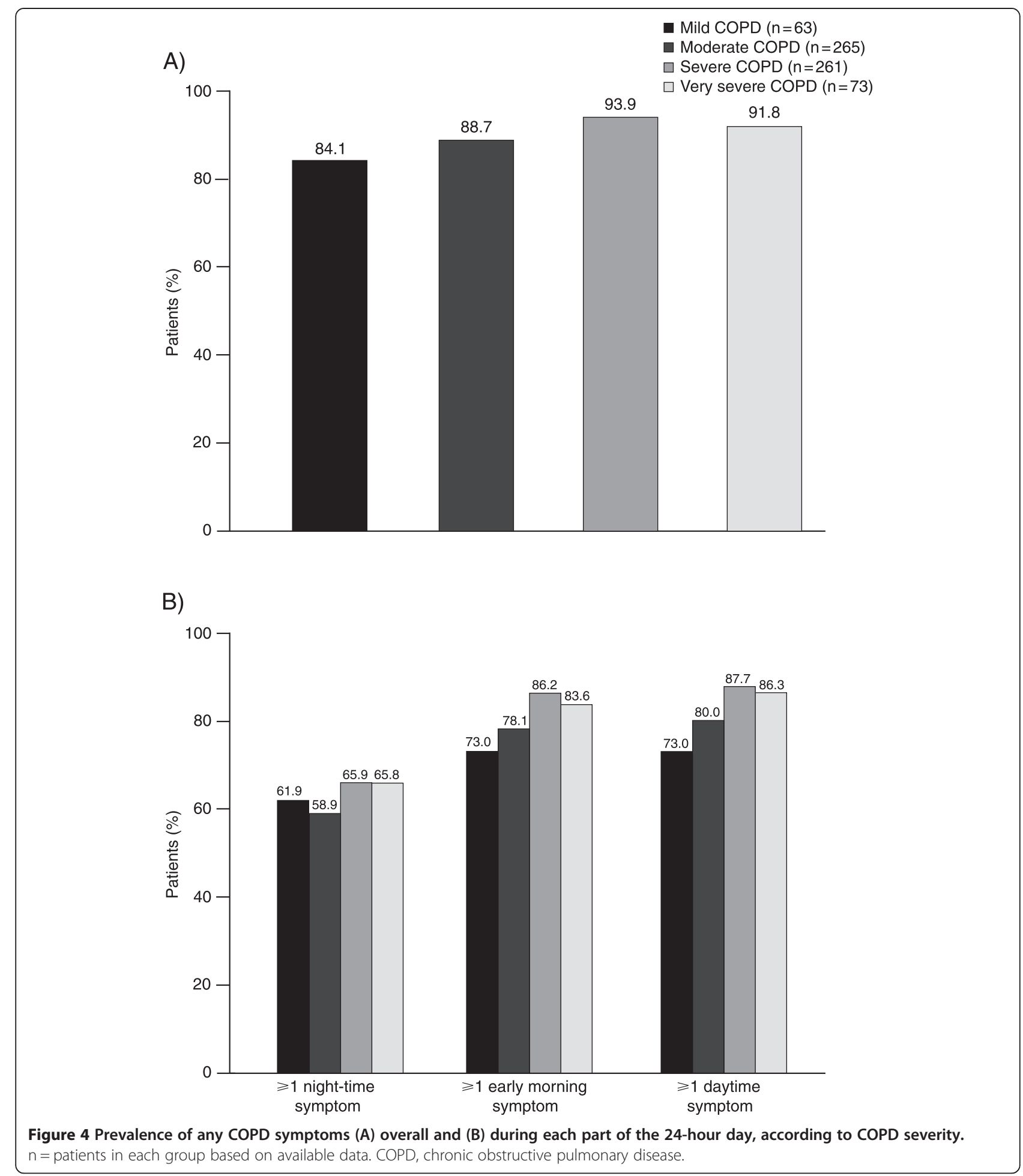

of health status. Moreover, anxiety and depression levels were also significantly higher in patients with symptoms compared with patients without symptoms. In general, anxiety levels tended to be highest in patients who had any combination of night-time symptoms and depression levels were highest in patients with any combination of night-time/early morning symptoms. Depression is a common comorbidity in patients with COPD [2] and patients with severe COPD have a 2.5 -fold higher risk of depression compared with matched controls [31]. Comorbid depression is associated with an increased risk of exacerbation and mortality in patients with 
Table 4 Patient-reported outcomes in patients with/without COPD symptoms during each part of the 24-hour day

\begin{tabular}{|c|c|c|c|c|c|c|c|c|c|}
\hline \multirow[b]{2}{*}{$\begin{array}{l}\text { Patient-reported } \\
\text { outcome }\end{array}$} & \multicolumn{2}{|c|}{ Night-time symptoms } & \multirow[b]{2}{*}{$p$-value } & \multicolumn{2}{|c|}{ Early morning symptoms } & \multirow[b]{2}{*}{$p$-value } & \multicolumn{2}{|c|}{ Daytime symptoms } & \multirow[b]{2}{*}{ p-value } \\
\hline & No symptoms & $\geq 1$ symptom & & No symptoms & $\geq 1$ symptom & & No symptoms & $\geq 1$ symptom & \\
\hline mMRC grade, & 1.6 & 1.9 & $<0.001$ & 1.4 & 1.9 & $<0.001$ & 1.4 & 1.9 & $<0.001$ \\
\hline \multirow[t]{2}{*}{ mean $(95 \% \mathrm{Cl})$} & $(1.5,1.7)$ & $(1.8,2.0)$ & & $(1.2,1.5)$ & $(1.8,2.0)$ & & $(1.2,1.6)$ & $(1.8,2.0)$ & \\
\hline & $(n=265)$ & $(n=457)$ & & $(n=134)$ & $(n=591)$ & & $(n=124)$ & $(n=600)$ & \\
\hline CAT score, & 11.6 & 19.3 & $<0.001$ & 9.8 & 18.1 & $<0.001$ & 10.0 & 17.9 & $<0.001$ \\
\hline \multirow[t]{2}{*}{ mean $(95 \% \mathrm{Cl})$} & $(10.8,12.4)$ & $(18.6,20.0)$ & & $(8.8,10.9)$ & $(17.4,18.7)$ & & $(8.9,11.1)$ & $(17.3,18.5)$ & \\
\hline & $(n=263)$ & $(n=455)$ & & $(n=133)$ & $(n=588)$ & & $(n=124)$ & $(n=596)$ & \\
\hline HADS anxiety score, & 4.6 & 6.9 & $<0.001$ & 4.1 & 6.5 & $<0.001$ & 4.2 & 6.5 & $<0.001$ \\
\hline \multirow[t]{2}{*}{ mean (95\% Cl) } & $(4.1,5.1)$ & $(6.5,7.3)$ & & $(3.4,4.7)$ & $(6.2,6.9)$ & & $(3.5,4.8)$ & $(6.1,6.8)$ & \\
\hline & $(n=262)$ & $(n=445)$ & & $(n=133)$ & $(n=577)$ & & $(n=123)$ & $(n=586)$ & \\
\hline HADS depression score, & 4.2 & 6.2 & $<0.001$ & 3.4 & 6.0 & $<0.001$ & 3.7 & 5.9 & $<0.001$ \\
\hline \multirow[t]{2}{*}{ mean $(95 \% \mathrm{Cl})$} & $(3.8,4.6)$ & $(5.8,6.6)$ & & $(2.9,4.0)$ & $(5.6,6.3)$ & & $(3.1,4.4)$ & $(5.5,6.2)$ & \\
\hline & $(n=263)$ & $(n=448)$ & & $(n=132)$ & $(n=582)$ & & $(n=123)$ & $(n=590)$ & \\
\hline CASIS score, & 33.6 & 50.2 & $<0.001$ & 34.4 & 46.3 & $<0.001$ & 34.2 & 46.2 & $<0.001$ \\
\hline \multirow[t]{2}{*}{ mean $(95 \% \mathrm{Cl})$} & $(31.9,35.2)$ & $(48.4,52.0)$ & & $(31.7,37.1)$ & $(44.8,47.9)$ & & $(31.4,37.0)$ & $(44.7,47.8)$ & \\
\hline & $(n=260)$ & $(n=449)$ & & $(n=131)$ & $(n=581)$ & & $(n=122)$ & $(n=589)$ & \\
\hline
\end{tabular}

$P$ values determined using Wilcoxon rank-sum test versus no symptoms in each period.

$\mathrm{n}=$ patients with available data for each outcome.

CASIS, COPD and Asthma Sleep Impact Scale; CAT, COPD Assessment Test; Cl, confidence interval; COPD, chronic obstructive pulmonary disease; HADS, Hospital Anxiety and Depression Scale; mMRC, modified Medical Research Council.

COPD [32]. Since symptoms of depression tend to be worse in the morning we cannot rule out that higher levels of depression contribute to night-time and morning COPD symptoms. Of note, examining questions on COPD symptoms and the HADS questionnaire does not reveal common items, making confounding by wording unlikely. Finally, a similar pattern in the magnitude of HADS scores and symptom combinations was observed in patients with no medical history of anxiety or depression. Sleep was also significantly impaired in patients with symptoms in any part of the 24-hour day compared with patients without symptoms. As expected, the greatest impairment was observed in patients with night-time symptoms. Poor sleep quality or sleep disturbance in patients with COPD has been shown to be associated with worse health status, more exacerbations, increased healthcare resource utilisation and increased mortality $[7,33]$. In this study, we also observed a significant relationship between symptoms in any part of the 24-hour day and physical activity levels: patients who were sedentary had more symptoms in each period than patients who were even moderately active. This may be important as low physical activity levels are significantly associated with poor quality of life and increased incidence of depression in patients with COPD [34] and have been shown to be a strong predictor of mortality in patients with COPD [35,36], and improving physical activity is an important goal in the treatment of COPD [9].
Overall, our results support previous studies showing that symptoms during the morning and the night-time are independently associated with worse outcomes in patients with COPD $[7,13]$. COPD symptoms when getting up in the morning have been shown to be independently associated with worse health status and more exacerbations, and have a negative impact on daily activities [13]. Similarly, patients with night-time symptoms had significantly worse breathlessness and health status and were more likely to have morning symptoms than patients without night-time symptoms, even when these analyses were controlled for confounding factors such as disease severity [7]. Our results extend these studies by demonstrating that there is an inter-relationship between symptoms in each part of the 24-hour day and that symptoms in any part of the day are associated with worse patientreported outcomes.

While these results demonstrate significant relationships between symptoms in each part of the 24-hour day and various aspects of patients' well-being, the analyses do not take into account confounding factors such as disease severity or comorbid conditions, which may also impact on patient-reported outcomes. Furthermore, no causal relationship can be inferred from the analyses as this was an observational study. Further investigation of the specific relationship between symptoms in each part of the 24-hour day and each outcome is required to establish whether symptoms are independently associated 


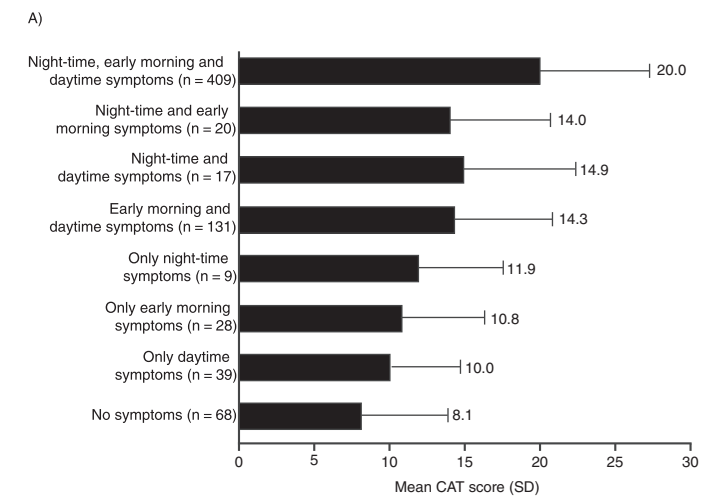

B)

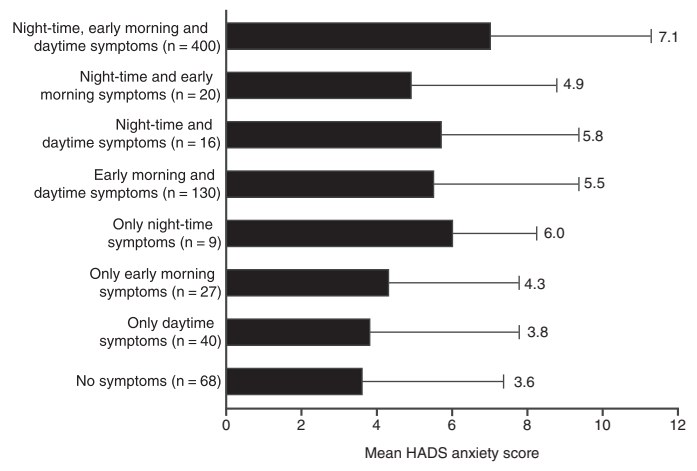

C)

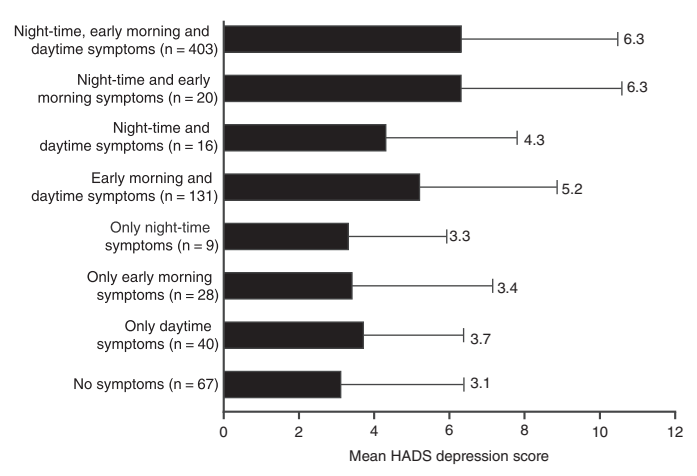

D)

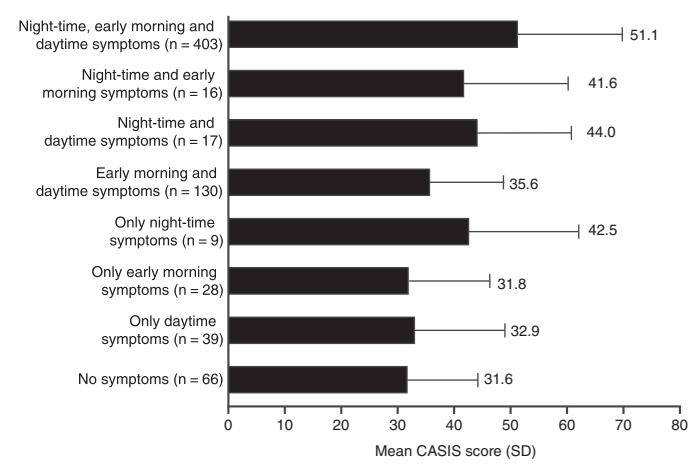

Figure 5 (A) Health status, (B) anxiety, (C) depression and (D) sleep quality according to each combination of 24-hour COPD symptoms. $\mathrm{n}=$ patients with available data for each outcome. CASIS, COPD and Asthma Sleep Impact Scale; CAT, COPD Assessment Test; COPD, chronic obstructive pulmonary disease; HADS, Hospital Anxiety and Depression Scale; SD, standard deviation.

with the outcome, irrespective of underlying disease. While this study enrolled patients with mild to very severe COPD, only patients being treated in clinical practice (both primary care and specialist centres) were assessed. As such, the relevance of these observations for the wider population of patients with COPD, including those with undiagnosed COPD, requires further consideration.

\section{Conclusions}

The results of this study demonstrate that despite receiving treatment for COPD, more than half of patients continued to have symptoms throughout the whole 24-hour day, including during the night-time and early morning periods. The relationship between night-time, early morning and daytime symptoms was observed irrespective of the severity of airflow obstruction. Patients with symptoms during any part of the 24-hour day also had significantly worse outcomes across a range of measures that impact on daily living, including health status, anxiety and depression levels and sleep quality compared with patients without symptoms. This suggests that current approaches to managing COPD may not adequately control symptoms, which can impact on a patient's overall well-being. Newer therapies, including long-acting bronchodilators that are administered twicedaily or ultra-long-acting bronchodilators, may be useful in improving symptom control during the night-time, whereas those with a rapid onset of action may have advantages in controlling early morning symptoms. It is important for physicians to manage patients' symptoms throughout the 24-hour day, even in those with mild airflow obstruction.

\section{Additional files}

\section{Additional file 1: ASSESS study investigators. Details of study} investigators.

Additional file 2: Country approval authorities. Details of approval authorities for each country.

Additional file 3: (A) Anxiety and (B) depression according to each combination of 24-hour COPD symptoms in patients without anxiety/depression. Analyses of HADS anxiety and depression scores in patients with no medical history of anxiety or depression.

\section{Abbreviations}

BMI: Body mass index; CASIS: COPD and Asthma Sleep Impact Scale;

CAT: COPD assessment test; COPD: Chronic obstructive pulmonary disease; $\mathrm{FEV}_{1}$ : Forced expiratory volume in 1 second; GOLD: Global Initiative for Chronic Obstructive Lung Disease; HADS: Hospital Anxiety and Depression 
Score; ICS: Inhaled corticosteroids; LABA: Long-acting $\beta_{2}$-agonist; LAMA: Long-acting muscarinic antagonist; mMRC: modified Medical Research Council; PDE4: Phosphodiesterase 4; SABA: Short-acting $\beta_{2}$-agonist; SAMA: Short-acting muscarinic antagonist; SD: Standard deviation.

\section{Competing interests}

Marc Miravitlles has received speaker fees from Almirall, Boehringer Ingelheim, Pfizer, AstraZeneca, Chiesi, Esteve, GlaxoSmithKline, Menarini, Talecris-Grifols, Takeda-Nycomed, and Novartis, and consulting fees from Almirall, Boehringer Ingelheim, Pfizer, GlaxoSmithKline, Gebro Pharma, MedImmune, Novartis, Talecris-Grifols and Takeda-Nycomed. Heinrich Worth has received speaker fees from Almirall, Bayer, Boehringer Ingelheim, AstraZeneca, Bionorica, Chiesi, GlaxoSmithKline, Klosterfrau, Berlin Chemie, Novartis, Takeda and consulting fees from Almirall, Berlin Chemie, Mundipharma, Bionorica, Intermune, Novartis and Takeda. Juan José Soler Cataluña has received speaker fees from Almirall, AstraZeneca, Bayer Schering, Boehringer Ingelheim, Esteve, Ferrer, GlaxoSmithKline, Merck Sharp \& Dohme, Novartis, Takeda and Pfizer, and consulting fees from Almirall, Boehringer Ingelheim, Pfizer, GlaxoSmithKline, AstraZeneca, Bayer Schering, Ferrer, Novartis, Merck Sharp \& Dohme, Uriach and Takeda.

David Price has served on advisory boards for Aerocrine, Almirall, Amgen, AstraZeneca, Boehringer Ingelheim, Chiesi, Meda, Mundipharma, Napp, Novartis, and Teva. He has consultant arrangements with Almirall, Amgen, AstraZeneca, Boehringer Ingelheim, Chiesi, GlaxoSmithKline, Meda, Mundipharma, Napp, Novartis, Pfizer, and Teva. He or his research team has received grants (or grants pending) and support for research in respiratory disease from the following organizations in the last 5 years: UK National Health Service, British Lung Foundation, Aerocrine, AstraZeneca, Boehringer Ingelheim, Chiesi, Eli Lilly, GlaxoSmithKline, Meda, Merck, Mundipharma, Novartis, Orion, Pfizer, Respiratory Effectiveness Group, Takeda, Teva and Zentiva. He has received unrestricted funding for investigator-initiated studies from Aerocrine, AKL Ltd, Almirall, Boehringer Ingelheim, Chiesi, Meda, Mundipharma, Napp, Novartis, Orion, Takeda, Teva, Zentiva. He has received funding for patient enrollment or completion of research from Almirall, Chiesi, Teva and Zentiva. He has received payments for lectures/speaking from Almirall, AstraZeneca, Boehringer Ingelheim, Chiesi, Cipla, GlaxoSmithKline, Kyorin, Meda, Merck, Mundipharma, Novartis, Pfizer, Skyepharma, Takeda and Teva; travel/ accommodations/meeting expenses from Aerocrine, Boehringer Ingelheim, Mundipharma, Napp, Novartis and Teva; manuscript preparation from Mundipharma and Teva; development of educational materials from GlaxoSmithKline and Novartis. He has patents and shares with AKL Ltd and owns $80 \%$ of Research in Real Life Ltd and its subsidiary social enterprise Optimum Patient Care.

Fernando De Benedetto has received over the past 5 years fees for speaking, participation in advisory boards or consulting from Almirall, Biofutura, Boehringer Ingelheim, Chiesi, GlaxoSmithKline, Novartis, Nycomed-Takeda. Nicolas Roche has received over the past 5 years (i) fees for speaking, organising education, participation in advisory boards or consulting from Almirall, Altana Pharma-Nycomed-Takeda, AstraZeneca, Boehringer Ingelheim, Chiesi, GlaxoSmithKline, MEDA, MSD-Chibret, Mundipharma, Novartis, Pfizer, Teva: (ii) research grants from Novartis, Nycomed, Boehringer Ingelheim and Pfizer. Nina Skavlan Godtfredsen has received honoraria from Almirall for participating in Danish and Nordic advisory boards.

Thys van der Molen has no competing interests to declare. Claes-Göran Löfdahl has received some reimbursement for lectures and ad-hoc advisory boards from Almirall, AstraZeneca, Boehringer Ingelheim, Novartis and Takeda.

Laura Padullés and Anna Ribera are employees of Almirall, Barcelona, Spain.

\section{Authors' contributions}

MM was the co-ordinating investigator of the study, contributed to the design of the study and to the analysis and interpretation of data, was involved in drafting the manuscript, revised it for intellectual content and provided final approval to submit. HW was a country co-ordinator for the study, contributed to interpretation of the data, revised the manuscript for intellectual content and provided final approval to submit. JJSC was a country co-ordinator for the study, contributed to interpretation of the data, revised the manuscript for intellectual content and provided final approval to submit. DP was a country co-ordinator for the study, contributed to interpretation of the data, revised the manuscript for intellectual content and provided final approval to submit. FdB was a country co-ordinator for the study, contributed to interpretation of the data, revised the manuscript for intellectual content and provided final approval to submit. NR was a country co-ordinator for the study, contributed to interpretation of the data, revised the manuscript for intellectual content and provided final approval to submit. NSG was a country co-ordinator for the study, contributed to interpretation of the data, revised the manuscript for intellectual content and provided final approval to submit. TvdM was a country co-ordinator for the study, contributed to interpretation of the data, revised the manuscript for intellectual content and provided final approval to submit. C-GL was a country co-ordinator for the study, contributed to interpretation of the data, revised the manuscript for intellectual content and provided final approval to submit. LP and AR contributed to the analysis and interpretation of data, were involved in drafting the manuscript, revised it for intellectual content and provided final approval to submit. All authors had full access to the data and take full responsibility for the content of the manuscript, including the data and analysis.

\section{Acknowledgements}

The authors would like to thank the study investigators at each of the participating centres for their contribution to the study. The full list of study investigators is available in Additional file 1. We would also like to thank Deborah McGregor, PhD, of Complete Medical Communications, who provided medical writing support funded by Almirall, S.A. Barcelona, Spain. This study was funded by Almirall S.A., Barcelona, Spain. The study sponsor was involved in the design of the study, analysis of the data, review of the data, and review and approval of the manuscript. The sponsors placed no restrictions on statements made in the final version of the manuscript or on the decision to submit the manuscript for publication and all authors had full access to the data.

\section{Author details}

${ }^{1}$ Pneumology Department, Hospital Universitari Vall d'Hebron, Ciber de Enfermedades Respiratorias (CIBERES), P. de la Vall d'Hebron, 119-129, Barcelona, Spain. ${ }^{2}$ Medical Department I, Fürth Hospital, Fürth, Germany. ${ }^{3}$ Servicio de Neumología, Hospital Arnau de Vilanova, Valencia, Spain. ${ }^{4}$ Centre of Academic Primary Care, University of Aberdeen, Aberdeen, UK.

${ }^{5}$ Pneumology Unit, Ospedale Clinicizzato SS. Annunziata, Chieti, Italy. ${ }^{6}$ Cochin Hospital, Paris Descartes University, Paris, France. ${ }^{7}$ Department of Respiratory Medicine, Bispebjerg University Hospital, Copenhagen, Denmark. ${ }^{8}$ University of Groningen, University Medical Center Groningen, Groningen, The Netherlands. ${ }^{9}$ Department of Respiratory Medicine and Allergology, Lund University Hospital, Lund, Sweden. ${ }^{10}$ Medical Affairs, Almirall, Barcelona, Spain.

Received: 14 July 2014 Accepted: 30 September 2014

Published online: 21 October 2014

\section{References}

1. Decramer M, Janssens W, Miravitlles M: Chronic obstructive pulmonary disease. Lancet 2012, 379:1341-1351.

2. van der Molen T: Co-morbidities of COPD in primary care: frequency, relation to COPD, and treatment consequences. Prim Care Respir J 2010, 19:326-334.

3. Waatevik M, Skorge TD, Omenaas E, Bakke PS, Gulsvik A, Johannessen A: Increased prevalence of chronic obstructive pulmonary disease in a general population. Respir Med 2013, 107:1037-1045.

4. Miravitlles M, Anzueto A, Legnani D, Forstmeier L, Fargel M: Patient's perception of exacerbations of COPD-the PERCEIVE study. Respir Med 2007, 101:453-460.

5. Tsiligianni I, Kocks J, Tzanakis N, Siafakas N, van der Molen T: Factors that influence disease-specific quality of life or health status in patients with COPD: a review and meta-analysis of Pearson correlations. Prim Care Respir J 2011, 20:257-268.

6. Monteagudo M, Rodriguez-Blanco T, Llagostera M, Valero C, Bayona X, Ferrer M, Miravitlles M: Factors associated with changes in quality of life of COPD patients: a prospective study in primary care. Respir Med 2013, 107:1589-1597.

7. Price D, Small M, Milligan G, Higgins V, Garcia Gil E, Estruch J: Impact of night-time symptoms in COPD: a real-world study in five European countries. Int J Chron Obstruct Pulmon Dis 2013, 8:595-603. 
8. Roche $\mathrm{N}$, Chavannes $\mathrm{NH}$, Miravitlles M: COPD symptoms in the morning: impact, evaluation and management. Respir Res 2013, 14:112.

9. Vestbo J, Hurd SS, Agustí AG, Jones PW, Vogelmeier C, Anzueto A, Barnes PJ, Fabbri LM, Martinez FJ, Nishimura M, Stockley RA, Sin DD, Rodriguez-Roisin R: Global strategy for the diagnosis, management, and prevention of chronic obstructive pulmonary disease: GOLD executive summary. Am J Respir Crit Care Med 2013, 187:347-365.

10. Kessler R, Partridge MR, Miravitlles M, Cazzola M, Vogelmeier C, Leynaud D, Ostinelli J: Symptom variability in patients with severe COPD: a pan-European cross-sectional study. Eur Respir J 2011, 37:264-272.

11. Espinosa de los Monteros MJ, Pena C, Soto Hurtado EJ, Jareno J, Miravitlles M: Variability of respiratory symptoms in severe COPD. Arch Bronconeumol 2012, 48:3-7.

12. Partridge MR, Karlsson N, Small IR: Patient insight into the impact of chronic obstructive pulmonary disease in the morning: an internet survey. Curr Med Res Opin 2009, 25:2043-2048.

13. Roche N, Small M, Broomfield S, Higgins V, Pollard R: Real world COPD: association of morning symptoms with clinical and patient reported outcomes. COPD 2013, 10:679-686.

14. Lange P, Marott JL, Vestbo J, Nordestgaard BG: Prevalence of night-time dyspnoea in COPD and its implications for prognosis. Eur Respir J 2014, 43:1590-1598.

15. Global strategy for the diagnosis, management, and prevention of chronic obstructive pulmonary disease. http://www.goldcopd.com/ guidelines-global-strategy-for-diagnosis-management.html.

16. Bestall JC, Paul EA, Garrod R, Garnham R, Jones PW, Wedzicha JA: Usefulness of the Medical Research Council (MRC) dyspnoea scale as a measure of disability in patients with chronic obstructive pulmonary disease. Thorax 1999, 54:581-586.

17. Jones PW, Harding G, Berry P, Wiklund I, Chen WH, Kline LN: Development and first validation of the COPD Assessment Test. Eur Respir J 2009, 34:648-654.

18. Hemmann C: International experiences with the hospital anxiety and depression scale - a review of validation data and clinical results. J Psychosom Res 1997, 42:17-41.

19. Snaith R: The Hospital Anxiety and Depression (HADS) scale. Qual Life Newsletter 1993, 6:5-6.

20. White D, Leach C, Sims R, Atkinson M, Cottrell D: Validation of the hospital anxiety and depression scale for use with adolescents. Br J Psychiatry 1999, 175:452-454.

21. Zigmond AS, Snaith RP: The hospital anxiety and depression scale. Acta Psychiatr Scand 1983, 67:361-370.

22. Bjelland I, Dahl AA, Haug T, Neckelmann D: The validity of the hospital anxiety and depression scale. An updated literature review. J Psychosom Res 2002, 52:69-77.

23. Olsson I, Mykletun A, Dahl AA: The hospital anxiety and depression rating scale: a cross-sectional study of psychometrics and case finding abilities in general practice. BMC Psychiatry 2005, 5:46. 46.

24. Pokrzywinski RF, Meads DM, McKenna SP, Glendenning GA, Revicki DA: Development and psychometric assessment of the COPD and Asthma Sleep Impact Scale (CASIS). Health Qual Life Outcomes 2009, 7:98.

25. Miravitlles M, Iriberri M, Barrueco M, Lleonart M, Villarrubia E, Galera J: Usefulness of the LCOPD, CAFS and CASIS scales in understanding the impact of COPD on patients. Respiration 2013, 86:190-200.

26. Agusti A, Hedner J, Marin JM, Barbé F, Cazzola M, Rennard S: Night-time symptoms: a forgotten dimension of COPD. Eur Respir Rev 2011, 20:183-194.

27. Spengler CM, Shea SA: Endogenous circadian rhythm of pulmonary function in healthy humans. Am J Respir Crit Care Med 2000, 162:1038-1046.

28. Postma DS, Koëter GH, vd Mark TW, Reig RP, Sluiter HJ: The effects of oral slow-release terbutaline on the circadian variation in spirometry and arterial blood gas levels in patients with chronic airflow obstruction. Chest 1985, 87:653-657.

29. Casale $R$, Pasqualetti $P$ : Cosinor analysis of circadian peak expiratory flow variability in normal subjects, passive smokers, heavy smokers, patients with chronic obstructive pulmonary disease and patients with interstitial lung disease. Respiration 1997, 64:251-256.

30. Kon SS, Canavan JL, Jones SE, Nolan CM, Clark AL, Dickson MJ, Haselden BM, Polkey MI, Man WD: Minimum clinically important difference for the COPD Assessment Test: a prospective analysis. Lancet Respir Med 2014, 2:195-203.
31. van Manen JG, Bindels PJ, Dekker FW, IJzermans CJ, van der Zee JS, Schade E: Risk of depression in patients with chronic obstructive pulmonary disease and its determinants. Thorax 2002, 57:412-416.

32. Atlantis $E$, Fahey $P$, Cochrane $B$, Smith S: Bidirectional associations between clinically relevant depression or anxiety and COPD: a systematic review and meta-analysis. Chest 2013, 144:766-777.

33. Scharf SM, Maimon N, Simon-Tuval T, Bernhard-Scharf BJ, Reuveni H, Tarasiuk A Sleep quality predicts quality of life in chronic obstructive pulmonary disease. Int J Chron Obstruct Pulmon Dis 2011, 6:1-12.

34. Miravitlles M, Cantoni J, Naberan K: Factors associated with a low level of physical activity in patients with chronic obstructive pulmonary disease. Lung 2014, 192:259-265.

35. Waschki B, Kirsten A, Holz O, Muller KC, Meyer T, Watz H, Magnussen H: Physical activity is the strongest predictor of all-cause mortality in patients with COPD: a prospective cohort study. Chest 2011, 140:331-342.

36. Garcia-Rio F, Rojo B, Casitas R, Lores V, Madero R, Romero D, Galera R, Villasante C: Prognostic value of the objective measurement of daily physical activity in patients with COPD. Chest 2012, 142:338-346.

doi:10.1186/s12931-014-0122-1

Cite this article as: Miravitlles et al:: Observational study to characterise 24-hour COPD symptoms and their relationship with patient-reported outcomes: results from the ASSESS study. Respiratory Research 2014 15:122

\section{Submit your next manuscript to BioMed Central and take full advantage of:}

- Convenient online submission

- Thorough peer review

- No space constraints or color figure charges

- Immediate publication on acceptance

- Inclusion in PubMed, CAS, Scopus and Google Scholar

- Research which is freely available for redistribution 